\title{
Factors affecting the use of reforested sites by reptiles in cleared rainforest landscapes in tropical and subtropical
}

\author{
Australia \\ John J. Kanowski, Terry M. Reis, Carla P. Catterall and Scott D. Piper. \\ Rainforest Cooperative Research Centre, Environmental Sciences, Griffith University, \\ Nathan, QLD 4111 Australia \\ Corresponding author: John Kanowski (J.Kanowski@griffith.edu.au)
}

Citation details:

Kanowski, J., Reis, T., Catterall, C.P. and Piper, S. (2006) Factors affecting the use of reforested sites by reptiles in cleared rainforest landscapes in tropical and subtropical Australia. Restoration Ecology 14, 67-76.

\footnotetext{
ABSTRACT

Despite recent efforts to reforest cleared rainforest landscapes, in Australia and elsewhere, the value of reforested sites for rainforest-dependent reptiles is unknown. We surveyed the occurrence of reptiles in a range of reforestation types (monoculture and mixed species timber plantations, diverse 'ecological restoration' plantings and regrowth), as well as reference sites in pasture and rainforest, in tropical and subtropical Australia. We recorded 29 species of reptiles from 104 sites, including 15 rainforest-dependent species. Most rainforest reptiles were strongly associated with complex microhabitats (tree trunks, logs, rocks). The richness and abundance of rainforest-dependent reptiles varied between the different types of
} 
reforestation and between regions. In the tropics, rainforest reptiles were recorded in old timber plantations and ecological restoration plantings, but not in young timber plantations or regrowth. Rainforest reptiles were recorded in few reforested sites in the subtropics. The occurrence of rainforest-dependent reptiles in reforested sites appears to be influenced by (i) habitat structure, (ii) proximity to source populations in rainforest; and (iii) biogeography and historical differences in the extent of rainforest. Restoration of cleared land for rainforestdependent reptiles may require the development, or deliberate creation, of complex structural attributes and microhabitats in reforested sites. Where reforested sites are located away from rainforest, recolonization by rainforest reptiles may require the construction of corridors of suitable habitat between reforested sites and rainforest or the translocation of reptiles to reforested sites.

Keywords: restoration, habitat quality, isolation, lizards, snakes, monitoring 


\section{INTRODUCTION}

Australia supports a diverse reptile fauna of more than 800 species (Cogger \& Heatwole 1981; Cogger 2000), of which at least 55 species occur in rainforests in tropical and subtropical eastern Australia (Covacevich \& McDonald 1991a, 1993). Little is known of the ecology of most rainforest reptiles or their response to habitat loss and fragmentation (Covacevich \& McDonald 1993; Williams et al. 1996; although see Sumner et al. 1999). However, the extensive clearing of rainforest which followed European settlement of Australia would have greatly reduced populations of rainforest-dependent reptiles. An estimated $30-75 \%$ of a former 4 to 8 million hectares of rainforest has been cleared in Australia over the past 200 years (Webb \& Tracey 1981; Cofinas \& Creighton 2001).

In recent decades, there has been increasing interest in the reforestation of cleared rainforest landscapes, in Australia and elsewhere, for biodiversity conservation, timber production and catchment protection (Parrotta et al. 1997; Lamb 1998; Catterall et al. 2004). Approaches to reforestation range from monocultures of timber trees to diverse 'ecological restoration' plantings (Goosem \& Tucker 1995; Kooyman 1996; Lamb et al. 1997; Parrotta \& Knowles 1999). Large areas of abandoned farmland have also reverted to regrowth, often dominated by woody weeds, in many cleared rainforest landscapes (Catterall et al. 2004; Lugo \& Helmer 2004).

At present, we have limited understanding of the value of different types of reforestation for rainforest wildlife. Published studies display a strong bias towards birds, mammals and some invertebrate groups (see, e.g., references in Lamb 1998; Kanowski et al. 2005a). Almost nothing is known of the response of reptiles to reforestation in rainforest landscapes, apart from a few studies in successional habitats (Bowman et al. 1990; Heinen 1992; East et al. 1995). The response of reptiles to restoration might be expected to differ from other terrestrial 
vertebrates, given their relatively small size, often limited mobility and low energy and water requirements (Heatwole \& Taylor 1987; Nagy et al. 1999). Reptiles (as both predators and prey) are likely to play important roles in the development of faunal assemblages in reforested sites (Dial \& Roughgarden 1995; Schoener \& Spiller 1996), although the direct influence of reptiles on plant succession in reforested sites in Australia is likely to be very limited (Kanowski et al. 2004).

In this study, we examine the response of reptiles to different types of reforestation in cleared rainforest landscapes in tropical and subtropical eastern Australia. We are mostly interested in rainforest-dependent reptiles, as these taxa are likely to have been adversely affected by rainforest clearing and are typically the focus of conservation concern in these landscapes (Catterall et al. 2004). We consider the extent to which the responses of reptiles to reforestation are determined by the availability of suitable habitat and by the proximity of reforested sites to source populations in rainforest.

\section{METHODS}

\section{Study regions and design}

The study was conducted in two regions of eastern Australia: the upland plateau of the Atherton Tableland, in tropical north Queensland (lat $17-17^{\circ} 30^{\prime} \mathrm{S}$, long $145^{\circ} 30-145^{\circ} 45^{\prime} \mathrm{E}$; 500-850 m elevation; annual rainfall 1,300-3,000 mm); and the lowlands of subtropical south-east Queensland and north-east New South Wales (lat $26^{\circ} 30^{\prime}-29^{\circ} \mathrm{S}$, long $152^{\circ} 30^{\prime}-$ $153^{\circ} 30^{\prime} \mathrm{E} ; 10-400 \mathrm{~m}$ elevation; annual rainfall 1,100-2,000 mm). The two regions have broadly similar climates and support structurally similar rainforest types (Webb 1968). However, the subtropical study region extends over a much larger area and is subject to more environmental heterogeneity than the tropical study area. In both regions, rainforests are interspersed with other native vegetation (particularly eucalypt forests) and with areas cleared 
and developed for agriculture. Prior to European settlement, rainforest was more extensive in the tropics than the subtropics. Following clearing, approximately $7,500 \mathrm{~km}^{2}$ of rainforest remains in the tropics, compared with $3,400 \mathrm{~km}^{2}$ in the subtropical study area (Winter et al. 1987; Kanowski et al. 2003).

We surveyed four types of reforestation commonly practised in tropical and subtropical Australia: monoculture timber plantations, mixed-species cabinet timber plantations, ecological restoration plantings and unmanaged regrowth (Table 1). Most plantings were relatively young (5-20 years), except for monoculture plantations, in which we surveyed both young and old (40-70 years old) sites. Many of the old plantations had recruited a diverse understorey of rainforest plants, especially in the tropics (Keenan et al. 1997). Regrowth sites in the tropics contained a mixture of scramblers, shrubs and scattered trees, approximately 1020 years old. Subtropical regrowth sites were closed forest, 30-40 years old, dominated by the introduced species Cinnamomum camphora (camphor laurel) or Ligustrum lucidum and L.

sinense (privet). Reference sites were established in (i) cleared pasture and (ii) rainforest. Using information provided by revegetation practitioners, vegetation maps, aerial photography and local knowledge, we located 5-10 replicate sites of each treatment in each region, controlling where possible for climate, soil type and area (most sites $>4$ ha). A 0.3 ha study plot was established in a representative area at each site, away from edges where possible, on which all surveys of biota and measurements of habitat structure were conducted. Further details of the study design are given elsewhere (Kanowski et al. 2003; Catterall et al. 2004).

\section{Reptile sampling}

Reptiles (lizards and snakes) were sampled during 2000 and 2001 by a single observer (TR) who visited each site three times on different days during daylight hours. Tropical sites were 
visited once during October-November 2000 and twice during April-May 2001. Subtropical sites were visited once during February-March 2001 and twice during October-November 2001. As far as possible, site re-visits were at different times of day.

Plots were actively searched for reptiles (Blomberg \& Shine 1996) for 30 minutes each visit. Searches included observation of individuals on the surface of the ground layer and in the understorey, and turning of woody debris, rocks and leaf litter. Identification to species was not always possible for individuals not captured by hand, but most individuals could be identified to genus. The microhabitat in which each individual was located was recorded.

\section{Data analysis}

Differences in the reptile fauna amongst site types were analysed in terms of (i) total species richness, (ii) richness of the fauna classified by habitat preference ('rainforest' or 'mixed habitat'), (iii) total abundance, and (iv) the abundances of the more commonly recorded taxa (recorded at four or more sites in a region). Habitat preferences were based primarily on Covacevich and McDonald (1991a), but also Wilson and Knowles (1988), Cogger (2000) and Couper et al. (2000). Classifications were made separately for tropics and subtropics, based on regional habitat preferences in undisturbed vegetation. Rainforest reptiles were defined as those species which occur in rainforest and other vegetation types only where rainforest is in the immediate landscape, e.g., rainforest edges and in closely adjacent habitats. Mixed-habitat reptiles may occur in a range of vegetation types not necessarily proximate to rainforest. Individuals identified only as Saproscincus in the tropics and Eulamprus in the subtropics were considered rainforest-dependent, where the individuals observed were clearly referable only to rainforest-dependent taxa. Analysis of Variance (ANOVA) was used to compare site types in each region, with $p$ values determined by a randomization test because of the 
unbalanced design (Edgington 1980). Pasture sites (where very few reptiles were recorded) were excluded from analyses.

While the study was not designed to control for landscape forest cover, sites varied in their distance to rainforest. Based on the distribution of these distances, sites were arbitrarily considered 'close' to rainforest if they were adjacent or within $400 \mathrm{~m}$ of extensive or remnant ( $>5$ ha) rainforest; other sites were considered 'distant' from rainforest (most were $>1 \mathrm{~km}$ from rainforest). Numbers of sites in each category were often low and varied between site types, precluding statistical analysis of the effect of proximity to rainforest on reptile richness and abundance, and only trends in these results are reported.

\section{RESULTS}

\section{Regional overview}

Seven families, 18 genera and 29 species of reptiles were recorded in the 104 sites surveyed in this study (Table 2). Of these, 10 genera and 12 species of reptiles from five families were recorded in the tropics (including six rainforest-dependent species), while 13 genera and 19 species from six families were recorded in the subtropics (including nine rainforest-dependent species). Most species and individuals recorded were small lizards (Scincidae). Although more species were recorded from the more extensive subtropical study area, the mean species richness of reptiles per site was greater in the tropics than the subtropics for most site types (Fig. 1). Reptile abundance varied widely between site types and between regions (Fig. 2), but very few reptiles were recorded in pasture. 


\section{Comparisons between site types: species richness and abundance}

\section{Tropics}

Within the tropics, the richness of all reptile species, and both rainforest-dependent and mixed-habitat species, varied significantly between site types (Table 3). Rainforest species were recorded in all rainforest reference sites, nine of 10 old plantations and seven of 10 restoration plantings, but not in other sites (Fig. 1). Mixed-habitat reptiles were recorded in all site types, but were especially rich and abundant in young monoculture plantations and ecological restoration plantings. Total richness was highest in rainforest reference sites, young and old monoculture plantations and ecological restoration sites.

Seven species of reptiles were recorded at four or more sites. The abundances of two rainforest reptiles, Eulamprus tigrinus and the Gnypetoscincus queenslandiae (prickly forest skink), varied significantly between site types (Table 3), the former only recorded in rainforest reference sites, the latter in rainforest reference sites and, less commonly, old monoculture plantations (Table 2). A third rainforest skink, Saproscincus basiliscus, tended to be most common in ecological restoration and old monoculture plantations sites $(p=0.093)$; while Hypsilurus boydii (Boyd's forest dragon) tended to be most common in old plantations $(p=0.094)$. The mixed-habitat skink, Carlia rubrigularis, was significantly more abundant in young monoculture plantations, mixed species plantations and ecological restoration sites than old monoculture plantations and rainforest reference sites.

\section{Subtropics}

The richness of rainforest-dependent species varied significantly between site types in the subtropics (Table 3). Rainforest species were recorded at six of 10 rainforest reference sites, but only in five of the 39 reforested sites: two young plantations, two old plantations and a regrowth site (Fig. 1). Total species richness and total reptile abundance also showed trends in 
abundance between site types in the subtropics ( $p<0.1$ for both analyses). Total species richness tended to be highest in rainforest reference sites and ecological restoration plantings, while total reptile abundance tended to be highest in regrowth, mixed species plantations and ecological restoration sites (Fig. 2). Mixed-habitat species were recorded in all site types except young monoculture plantations, although a considerable number of individuals were not able to be identified to species in reforested sites, including young plantations (Fig. 2). Two species of reptiles were recorded at four or more sites in the subtropics. Of these, only the rainforest skink Eulamprus murrayi varied significantly in abundance between site types

(Table 3). This species was recorded only at rainforest reference sites, although individuals of Eulamprus identified only to genus were also recorded in one old monoculture plantation. At the generic level, both Eulamprus and Lampropholis varied significantly between site types. Eulamprus was characteristic of rainforest reference sites, while Lampropholis was abundant within regrowth, mixed species plantations and ecological restoration sites (Table 2).

\section{Microhabitat use}

Most rainforest-dependent reptiles were associated with logs, rocks and trees (including tree trunks, buttresses and branches), particularly the genera Eulamprus, Hypsilurus and Gnypetoscincus. However, the rainforest skinks S. basiliscus, Lampropholis coggeri and $L$. couperi were mainly recorded from leaf litter. Mixed habitat reptiles were predominantly associated with leaf litter and grass (Table 4).

\section{Effect of proximity to rainforest}

In the tropics, rainforest-dependent reptiles were recorded in nine old plantations and seven restoration plantings. All the plantations and two of the seven restoration plantings were adjacent to rainforest, but all five 'distant' restoration sites where rainforest reptiles were recorded were linked to rainforest by vegetated riparian corridors. Litter-dwelling skinks $(S$. 
basiliscus and $L$. coggeri) were the only rainforest reptiles recorded at these 'distant' restoration sites. Rainforest reptiles were not recorded in restoration sites completely isolated from rainforest by pasture.

In the subtropics, rainforest reptiles were recorded at five reforested sites. Of these, three sites were located adjacent to rainforest. The other two sites (one young, one old monoculture plantation) were embedded within a matrix of plantations and strips of remnant rainforest that were contiguous with extensive rainforest. At both sites, rainforest reptiles were associated with coarse woody debris, a legacy of the original forest felled for plantation development.

\section{DISCUSSION}

\section{Comprehensiveness of survey and data limitations}

Based on latitudinal and altitudinal distributions of the fauna, we recorded six of the 12 and nine of 14 rainforest-dependent reptiles expected to occur in our tropical and subtropical study areas, respectively (Covacevich et al. 1982; Czechura \& Covacevich 1985; Covacevich \& McDonald 1991a, b; Cogger 2000). The rainforest species not represented in our surveys include three nocturnal lizards (Gekkonidae), two snakes (Elapidae) and a number of skinks (Scincidae). That our limited survey effort detected a considerable proportion of the rainforest-dependent reptiles in each region reflects both the paucity of reptiles amongst the Australian rainforest fauna, and the fact that most of the rainforest reptiles are diurnal and can be found under logs, in leaf litter, or close to the ground on tree trunks, and hence are relatively easy to locate.

Very few reptiles were recorded in pasture sites, although our results are confounded somewhat by the difficulties of observing reptiles amongst pasture. Pasture sites could be expected to support some mixed habitat reptiles, although both richness and abundance could be expected to be low in most sites, given their long history of intensive grazing (Woinarski \& 
Ash 2002). No reptiles were incidentally captured in pitfall traps in the same pasture sites during a concurrent study of invertebrates (Proctor et al. 2003), although small skinks were sometimes caught in these traps in reforested sites.

\section{The value of reforestation for rainforest reptiles}

The only types of reforestation which consistently supported rainforest reptiles were ecological restoration plantings and old timber plantations, and these only in the tropics. We suggest these results reflect two major factors: first, the structural attributes of the different types of reforestation, interacting with the habitat requirements of reptiles; and second, the proximity of sites to potential source populations in rainforest, interacting with the dispersal capacities of reptiles and the nature of the intervening matrix. Additionally, regional differences in the response of reptiles to reforestation may be related to biogeographical and historical differences in the extent of rainforest. These issues will be discussed below.

\section{Role of habitat structure and microhabitat preference}

The different types of reforestation surveyed in this study varied greatly in the physical structure of their vegetation (Kanowski et al. 2003). Rainforest sites were characterised by a closed canopy, a relatively high density of trees and shrubs in a range of size classes, a variety of life-forms including epiphytes, lianas, and strangler figs, and a shrubby understorey with high volumes of coarse woody debris and leaf litter. Pasture sites lacked all these attributes, while the different styles of reforestation had developed them to varying degrees. In general, the structural similarity of reforested sites to rainforest increased from young monoculture and mixed species plantations, through ecological restoration plantings, to old timber plantations (tropics only). Old plantations in the subtropics tended to have a less complex structure, as a consequence of a more intensive silvicultural regime and, perhaps, a drier environment 
(Kanowski et al. 2003). Regrowth sites varied widely in structure, but were older and more forest-like in the subtropics than the tropics.

The trends in vegetation structure are broadly concordant with the use of reforested sites by rainforest reptiles, at least in the tropics, where the richness and abundance of rainforest reptiles increased from ecological restoration plantings to old plantations to rainforest. It is noteworthy that no rainforest reptiles were recorded in young monoculture or mixed species timber plantations, even though these sites had developed some of the structural attributes of rainforest. Consequently, rainforest reptiles appear to have a threshold response to the development of rainforest-like structural attributes in reforested sites. For example, in the tropics, rainforest reptiles were recorded in none of the 14 reforested sites where canopy cover was low ( $<60 \%$ : data from Kanowski et al. 2003), but in 16 of the 21 sites where canopy cover exceeded $60 \%$ (Fig. 3). Canopy cover may directly affect habitat quality for rainforest reptiles, because of its influence on light and thermal environments in the understorey. Different types of reforestation vary in the length of time from establishment to canopy closure. Dense ecological restoration plantings may achieve canopy closure within 3-5 years of establishment on favourable sites (Goosem \& Tucker 1995), whereas widely spaced timber plantations may take decades. A dense canopy may never be achieved in timber plantations subject to intensive thinning or comprised of sparsely-canopied trees, such as eucalypts (Kanowski et al. 2003). Canopy cover was also correlated with a number of other structural attributes of reforested sites (e.g., stem density, basal area, shrub cover), which may influence habitat suitability for reptiles (Kanowski et al. 2003). Few types of reforestation in rainforest lanscapes are sufficiently old to track the development of these structural attributes over time, but regrowth forests may acquire many of the structural attributes of intact forests within 50100 years (Aide et al. 2000; Guariguata \& Ostertag 2001). 
Reptiles strongly associated with the complex habitat features of rainforest were poorly represented in reforested sites. For example, the skink G. queenslandiae, which lives in and under decaying logs (Sumner et al. 1999), was recorded outside rainforest reference sites only in old plantations, the only sites to contain abundant large woody debris (Kanowski et al. 2003). Similarly, rainforest-dependent species of Eulamprus were almost entirely restricted to rainforest reference sites, presumably because mature strangler figs and large or hollow stems were virtually absent from reforested sites (these are the microhabitats typically associated with Eulamprus in rainforest: Ehmann 1992; see Table 2). The rainforest reptiles most commonly recorded in reforested sites were litter skinks (Saproscincus and Lampropholis). In rainforest, these species are reported to prefer the edges of small clearings and other canopy openings (Ehmann 1992). Their abundance in ecological restoration plantings and old plantations in the tropics may reflect the more open canopy of those sites compared with rainforest (Kanowski et al. 2003).

Role of proximity to remnant forest

The proximity of reforested sites to rainforest and the nature of the intervening landscape would be expected to impose a strong filter on the use of reforested sites by rainforest reptiles. Most lizards have small home ranges and are unlikely to disperse long distances, particularly when intervening habitat is unsuitable (Hokit et al. 1999; Stow et al. 2001; Osterwalder et al. 2004). In the present study, all reforested sites where rainforest reptiles were recorded were adjacent to rainforest, or connected to rainforest by forested habitat (vegetated corridors or a matrix of old timber plantations and remnant forest).

\section{Regional differences in the use of reforested sites by reptiles}

Habitat structure and proximity to rainforest do not entirely explain the relative absence of rainforest reptiles from reforested sites in the subtropics. For example, old plantations and 
restoration plantings in the subtropics had often developed intermediate levels of structural complexity and a number of sites were located adjacent to rainforest or within a matrix of plantations and rainforest. Instead, these results may reflect the relatively low richness of rainforest reptiles in subtropical rainforest sites (Fig. 1). Indeed, most vertebrate groups are relatively depauperate in subtropical Australian rainforests compared with the tropics, a pattern thought to reflect the smaller area of rainforest in the subtropics, especially during the Pleistocene (Heatwole 1987; Winter 1988). Biogeographical differences may be exacerbated by the greater extent and age of clearing in the subtropics (Adam 1992). These factors may contribute to the low rate of recolonization of reforested sites by rainforest reptiles in the subtropics.

\section{Management implications}

\section{Improving the value of restored sites for reptiles}

The results of this study suggest that rainforest reptiles are constrained from recolonizing reforested sites by a lack of suitable habitat and by the isolation of sites from source populations in rainforest, although biogeographical and historical factors also influence the potential for recolonization in particular regions. Therefore, to improve the value of reforested sites for reptiles, key habitat attributes which would be slow or unlikely to develop on reforested sites under natural processes could be introduced during the establishment phase. For example, a number of projects which have sought to restore habitat for reptiles have added key microhabitats, including logs, rocks and burrows, to rehabilitated sites (Webb \& Shine 2000; Mac Nally et al. 2001; Nelson et al. 2002; Nichols \& Nichols 2003; Souter et al. 2004). These types of habitat enhancements are both simple and inexpensive and have been applied in at least one rainforest restoration project in tropical Australia (Grove \& Tucker 2000). However, certain structural features of rainforest which provide important habitat for 
reptiles, such as the strangler figs frequented by Eulamprus, would require complex engineering to create artificially on reforested sites. More fundamentally, the suitability of engineered sites for specialist reptiles may still be limited by other habitat factors such as microclimate and the availability of suitable food, and these factors are poorly known for most species. For example, we did not record the rainforest specialist log-dwelling skink $G$. queenslandiae in the tropical restoration project to which coarse woody debris had been added, although Grove and Tucker (2000) found these logs had been colonised by saproxylic beetles. Field experiments are needed to determine appropriate strategies for enhancing the value of reforested sites for reptiles with specialised habitat requirements.

Regardless of their habitat suitability, our results suggest that reforested sites completely isolated from rainforest are unlikely to be recolonized by rainforest reptiles. While the establishment of corridors linking reforested sites with remnant forest has been widely promoted as a solution to the problem of isolation, particularly in tropical and subtropical Australia (Tucker 2000; Scotts \& Drielsma 2002), it is not known whether corridors will be used by rainforest reptiles. Our data suggest that some litter-dwelling rainforest reptiles may readily disperse to reforested sites along vegetated creeks, but whether microhabitat specialists will disperse along these corridors is not yet known. Studies elsewhere suggest that long-distance dispersal of lizards and snakes along narrow riparian corridors is unlikely (Burbrink et al. 1998). Translocation of rainforest reptiles to reforested sites is a possible alternative strategy (e.g., Trenham \& Marsh 2002), although globally there are few examples of successful translocation programs involving reptiles (Dodd \& Siegel 1991) or indeed other taxa (Fischer \& Lindenmayer 2002). The success of translocation would rely on suitable habitat already being present at reforested sites, which would be difficult to determine a priori (see above). Translocation would also require explicit consideration of genetical conservation issues (Branch et al. 2003). 
Whatever strategy is adopted for enhancing the value of reforested sites for rainforest reptiles, monitoring the outcome will be necessary to determine its success. Developing appropriate monitoring strategies for reptiles requires considerable thought and experimentation under an adaptive management framework (Mitchener 1997; Block et al. 2001; Towns \& Ferreira 2001; Holl \& Cairns 2002). The selection of target taxa and monitoring protocols is particularly challenging when monitoring programs are to be conducted by individuals or groups without specialist training, as is often the case in reforested sites in Australia (Freeman 2004). However, it is clear that the habitat value of reforested sites for reptiles cannot simply be extrapolated from surveys of other taxa. While some rainforest-dependent birds and invertebrates have been recorded in all types of reforestation surveyed in the present study and are therefore relatively quick to respond to reforestation efforts, rainforest-dependent reptiles in general do not show the same response (Catterall et al. 2004; Kanowski et al. 2005b). Studies of rehabilitated mine sites in Australia have also reported that reptiles are relatively 'slow' to respond to reforestation compared with other fauna, a response attributed to the slow rate of development of microhabitats required by reptiles and the low mobility of reptiles compared with other taxa (Twigg \& Fox 1991; Nichols \& Nichols 2003).

Ideally, a monitoring program would target reptiles that are both sensitive to habitat change and cost-effective to survey (see Read 2002; Goodall et al. 2004, for Australian reptile examples). In the tropics, the skink G. queenslandiae meets both criteria, as it is strongly associated with large rotting logs, one of the habitat features of rainforest, and it is easy to locate and identify when present (Sumner et al. 1999; this study). However, large logs may be very scarce in regenerating and reforested sites, typically for decades (Guariguata \& Ostertag 2001; Kanowski et al. 2003). Reptiles which are less demanding in their microhabitat requirements, such as the litter skinks Saproscincus and Lampropholis, may be more suitable 
indicators of the progress of reforested sites towards reference conditions. Unfortunately, species in these genera can be difficult to identify in the field. Enhancing the value of reforestation for rainforest-dependent reptiles and monitoring the outcomes of these efforts still present significant challenges for ecologists and resource managers.

\section{ACKNOWLEDGEMENTS}

The study is part of the 'Quantifying the Biodiversity Values of Reforestation' project of the Rainforest Cooperative Research Centre. Grant Wardell-Johnson (University of Queensland) and Heather Proctor (University of Alberta) helped design and conduct the project. Steve Wilson (Queensland Museum) gave advice on species distributions. Thanks to landholders, managers, reforestation practitioners, volunteers and others who have contributed to the study. We acknowledge Jim Miller and two reviewers for helpful comments on the manuscript.

\section{LITERATURE CITED}

Adam, P. 1992. Australian Rainforests. Oxford University Press, Oxford.

Aide, T. M., Zimmerman, J. K., Pascarella, J. B., Rivera, L., and H. Marcano-Vega. 2000. Forest regeneration in a chronosequence of tropical abandoned pastures: implications for restoration ecology. Restoration Ecology 8:328-338.

Block, W. M., Franklin, A. B., Ward Jr., J. P., Ganey, J. L., and G. C. White. 2001. Design and implementation of monitoring studies to elucidate the success of ecological restoration on wildlife. Restoration Ecology 9:293-303.

Blomberg, S., and R. Shine. 1996. Reptiles. Pages 218-226 in W. J. Sutherland, editor. Ecological census techniques: a handbook. Cambridge University Press, Cambridge. 
Bowman, D. M. J. S., Woinarski, J. C. Z., Sands, D. P. A., Wells, A,. and V. J. McShane. 1990. Slash-and-burn agriculture in the wet coastal lowlands of Papua New Guinea: response of birds, butterflies and reptiles. Journal of Biogeography 17:227-239.

Branch L. C., Clark A. M., Moler P. E., and B. W. Bowen. 2003. Fragmented landscapes, habitat specificity, and conservation genetics of three lizards in Florida scrub. Conservation Genetics 4:199-212.

Burbrink, F. T., Phillips, C. A., and E. J. Heske. 1998. A riparian zone in southern Illinois as a potential dispersal corridor for reptiles and amphibians. Biological Conservation 86:107-115.

Catterall, C. P., Kanowski, J., Wardell-Johnson, G. W., Proctor, H., Reis, T., Harrison, D. and N. I. J. Tucker. 2004. Quantifying the biodiversity values of reforestation: perspectives, design issues and outcomes in Australian rainforest landscapes. Pages 359-393 in D. Lunney, editor. Conservation of Australia's forest fauna, volume 2. Royal Zoological Society of New South Wales, Sydney.

Cofinas, M., and C. Creighton. 2001. Australian native vegetation assessment 2001. National Land and Water Resources Audit, Commonwealth of Australia, Canberra.

Cogger, H. G. 2000. Reptiles and amphibians of Australia. Reed New Holland, Sydney.

Cogger, H. G., and H. Heatwole. 1981. The Australian reptiles: origins, biogeography, distribution patterns and island evolution. Pages 1333-1373 in A. Keast, editor. Ecological biogeography of Australia. Junk, The Hague.

Couper, P., Covacevich, J., Janetzki, H., and K. R. McDonald. 2000. Lizards. Pages 203-233 in M. Ryan and C. Burwell, editors. Wildlife of tropical north Queensland. Queensland Museum, Brisbane. 
Covacevich, J., and K. R. McDonald. 1991a. Frogs and reptiles of tropical and subtropical eastern Australian rainforests: distribution patterns and conservation. Pages 281-309 in G. Werren and P. Kershaw, editors. The rainforest legacy: Australian national rainforests study: volume 2 - flora and fauna of the rainforests. Australian Government Publishing Service, Canberra.

Covacevich, J., and K. R. McDonald. 1991b. Reptiles. Pages 69-82 in H. A. Nix and M. A. Switzer, editors. Kowari 1: rainforest animals: atlas of vertebrates endemic to Australia's wet tropics. Australian National Parks and Wildlife Service, Canberra.

Covacevich, J., and K. R. McDonald. 1993. Distribution and conservation status of frogs and reptiles of Queensland rainforests. Memoirs of the Queensland Museum 34:189-199.

Covacevich, J., Ingram, G. J., and G. V. Czechura. 1982. Rare frogs and reptiles of Cape York Peninsula, Australia. Biological Conservation 22:283-294.

Czechura, G. V., and J. A. Covacevich. 1985. Poorly known reptiles in Queensland. Pages 471- 476 in G. Grigg, R. Shine and H. Ehmann, editors. Biology of Australasian frogs and reptiles. Royal Zoological Society, Sydney.

Dial, R., and J. Roughgarden. 1995. Experimental removal of insectivores from rain forest canopy: direct and indirect effects. Ecology 76:1821-1834.

Dodd Jr, C. K., and R. A. Seigel. 1991. Relocation, repatriation and translocation of amphibians and reptiles: are they conservation strategies that work?. Herpetologica 47:336-350.

East, K. T., East, M. R., and C. H. Daugherty. 1995. Ecological restoration and habitat relationships of reptiles on Stephens island, New Zealand. New Zealand Journal of Zoology 22:249-261.

Edgington, E. S. 1980. Randomization tests. Marcel Dekker, New York. 
Ehmann, H. 1992. Encyclopedia of Australian animals: reptiles. Angus and Robertson, Sydney.

Fischer, J., and D. B. Lindenmayer. 2000. An assessment of the published results of animal relocations. Biological Conservation 96:1-11.

Freeman, A. 2004. Constraints to community groups monitoring plants and animals in rainforest revegetation sites on the Atherton Tablelands of far north Queensland. Ecological Management and Restoration 5:199-204.

Goodall, K., Mathieson, M. and G. C. Smith. 2004. Ground-dwelling reptile assemblages in selectively harvested dry sclerophyll forest in south-east Queensland. Pages 875-887 in D. Lunney, editor. Conservation of Australia's forest fauna, volume 2. Royal Zoological Society of New South Wales, Sydney.

Goosem, S., and N. I. J. Tucker. 1995. Repairing the rainforest: theory and practice of rainforest reestablishment in north Queensland's wet tropics. Wet Tropics Management Authority, Cairns.

Grove, S. J., and N. I. J. Tucker. 2000. Importance of mature timber habitat in forest management and restoration: what can insects tell us? Ecological Management and Restoration 1:62-64.

Guariguata, M. R., and R. Ostertag. 2001. Neotropical secondary forest succession: changes in structural and functional characteristics. Forest Ecology and Management 148:185206.

Heatwole, H. 1987. Major components and distributions of the terrestrial fauna. Pages 101135 in G. R. Dyne and D. W. Walton, editors. Fauna of Australia: volume 1A. Australian Government Publishing Service, Canberra.

Heatwole, H., and J. Taylor. 1987. Ecology of reptiles. Surrey Beatty \& Sons, Sydney. 
Heinen, J. T. 1992. Comparisons of the leaf litter herpetofauna in abandoned cacao plantations and primary rain forest in Costa Rica: some implications for faunal restoration. Biotropica 24:431-439.

Hokit, D. G., Stith, B. M., and L. C. Branch. 1999. Effects of landscape structure in Florida scrub: a population perspective. Ecological Applications 9:124-134.

Holl, K. D., and J. Cairns Jr. 2002. Monitoring and appraisal. Pages 411-432 in M. R. Perrow and A. J. Davy, editors. Handbook of ecological restoration. Vol. 1. Cambridge University Press, Cambridge.

Kanowski, J., Catterall, C. P., Wardell-Johnson, G. W., Proctor, H. and T. Reis. 2003. Development of forest structure on cleared rainforest land in eastern Australia under different styles of reforestation. Forest Ecology and Management 183:265-280.

Kanowski, J., Catterall, C. P., Reis, T. and G. W. Wardell-Johnson. 2004. Animal-plant interactions in rainforest restoration in tropical and subtropical Australia. Pages 20-24 in J. Kanowski, C. P. Catterall, A. J. Dennis and D. A. Westcott, editors. Animal-plant interactions in rainforest conservation and restoration. Rainforest CRC, Cairns.

Kanowski, J., Catterall, C. P., and G. W. Wardell-Johnson. 2005a. Consequences of broadscale timber plantations for biodiversity in cleared rainforest landscapes of tropical and subtropical Australia. Forest Ecology and Management 208:359-372.

Kanowski, J., Catterall, C. P., Proctor, H., Reis, T., Tucker, N. I. J. and G. W. WardellJohnson. 2005b. Biodiversity values of timber plantations and restoration plantings for rainforest fauna in tropical and subtropical Australia. Pages 183-205 in P. D. Erskine, D. Lamb and M. Bristow, editors. Reforestation in the tropics and subtropics of Australia using rainforest tree species. Rural Industries Research and Development Corporation, Canberra, and Rainforest Cooperative Research Centre, Cairns. 
Keenan, R., Lamb, D., Woldring, O., Irvine, A., and R. Jensen. 1997. Restoration of plant biodiversity beneath tropical tree plantations in northern Australia. Forest Ecology and Management 99:117-131.

Kooyman, R. 1996. Growing rainforest. Rainforest restoration and regeneration recommendations for the humid subtropical region of northern NSW and south-east Qld. Greening Australia, Brisbane.

Lamb, D. 1998. Large-scale ecological restoration of degraded tropical forest lands: the potential role of timber plantations. Restoration Ecology 6:271-279.

Lamb, D., Parrotta, J. A., Keenan, R., and N. I. J. Tucker. 1997. Rejoining habitat remnants: restoring degraded rainforest lands. Pages 366-385 in W. F. Laurance and R. O. Bierregaard, editors. Tropical forest remnants. University of Chicago Press, Chicago.

Lugo, A. E., and E. Helmer. 2004. Emerging forests on abandoned land: Puerto Rico's new forests. Forest Ecology and Management 190:145-161.

Mac Nally, R., Parkinson, A., Horrocks, G., Conole, L. and C. Tzaros. 2001. Relationship between terrestrial vertebrate diversity, abundance and availability of coarse woody debris on south-eastern Australian floodplains. Biological Conservation 99:191-205.

Mitchener, W. K. 1997. Quantitatively evaluating restoration experiments: research design, statistical analysis, and data management considerations. Restoration Ecology 5:324337.

Nagy, K. A., Girard, I. A., and T. K. Brown. 1999. Energetics of free-ranging mammals, reptiles, and birds. Annual Review of Nutrition 19:247-277.

Nelson, N. A., Keall, S. N., Brown, D., and C. H. Daugherty. 2002. Establishing a new wild population of tuatara (Sphenodon guntheri). Conservation Biology 16:887-894. 
Nichols, O.G., and F. M. Nichols. 2003. Long-term trends in faunal recolonization after bauxite mining in the Jarrah forest of southwestern Australia. Restoration Ecology 11:261-272.

Osterwalder, K., Klingenböck, A., and R. Shine. 2004. Field studies on a social lizard: home range and social organization in an Australian skink, Egernia major. Austral Ecology 29:241-249.

Parrotta, J. A., and O. H. Knowles. 1999. Restoration of tropical moist forests on bauxitemined lands in the Brazilian Amazon. Restoration Ecology 7:103-116.

Parrotta, J. A., Turnbull, J. W., and N. Jones. 1997. Catalyzing native forest regeneration on degraded tropical lands. Forest Ecology and Management 99:1-7.

Proctor H. C., Kanowski, J., Reis, T., Catterall, C. P., and G. W. Wardell-Johnson. 2003. Does diversity beget diversity? A comparison between plant and leaf-litter invertebrate richness from pasture to rainforest. Records of the South Australian Museum Monograph Series 7:267-274.

Read, J. L. 2002. Experimental trial of Australian arid zone reptiles as early warning indicators of overgrazing by cattle. Austral Ecology 27:55-66.

Schoener, T. W., and D. A. Spiller. 1996. Devastation of prey diversity by experimentally introduced predators in the field. Nature 381:691-694.

Scotts, D., and M. Drielsma. 2002. Developing landscape frameworks for regional conservation planning; an approach integrating fauna spatial distributions and ecological principles. Pacific Conservation Biology 8:235-254.

Souter, N. J., Bull, C. M., and M. N. Hutchinson. 2004. Adding burrows to enhance a population of the endangered pygmy blue tongue lizard, Tiliqua adelaidensis. Biological Conservation 111:403-408. 
Stow, A. J., Sunnucks, P., Briscoe, D. A., and M. G. Gardner. 2001. The impact of habitat fragmentation on dispersal of Cunningham's skink (Egernia cunninghami): evidence from allelic and genotypic analyses of microsatellites. Molecular Ecology 10:867-878.

Sumner, J., Moritz, C., and R. Shine. 1999. Shrinking forest shrinks skink: morphological change in response to rainforest fragmentation in the prickly forest skink (Gnypetoscincus queenslandiae). Biological Conservation 91:159-167.

Towns, D. R., and S. M. Ferreira. 2001. Conservation of New Zealand lizards (Lacertilia: Scincidae) by translocation of small populations. Biological Conservation 98:211-222.

Trenham, P. C., and D. M. Marsh. 2002. Amphibian translocation programs: reply to Seigel and Dodd. Conservation Biology 16:555-556.

Tucker, N. I. J. 2000. Linkage restoration: interpreting fragmentation theory for the design of a rainforest linkage in the humid Wet Tropics of north-eastern Queensland. Ecological Management and Restoration 1:35-41.

Twigg, L. E., and B. J. Fox. 1991. Recolonization of regenerating open forest by terrestrial lizards following sand mining. Australian Journal of Ecology 16:137-148.

Webb, J. K., and R. Shine. 2000. Paving the way for habitat restoration: can artificial rocks restore degraded habitats of endangered reptiles? Biological Conservation 92:93-99.

Webb, L. J. 1968. Environmental relationships of the structural types of Australian rain forest vegetation. Ecology 49:296-311.

Webb, L. J., and J. G. Tracey. 1981. Australia's rainforests. patterns and change. Pages 607694 in A. Keast, editor. Ecological biogeography of Australia. Junk, The Hague.

Williams, S. E., Pearson, R. G., and P. J. Walsh. 1996. Distributions and biodiversity of the 
terrestrial vertebrates of Australia's Wet Tropics: a review of current knowledge. Pacific Conservation Biology 2:327-362.

Wilson, S. K., and D. G. Knowles. 1988. Australia's reptiles: a photographic reference to the terrestrial reptiles of Australia. Collins, Sydney.

Winter, J. W. 1988. Ecological specialization of mammals in Australian tropical and subtropical rainforest: refugial or ecological determinism? Proceedings of the Ecological Society of Australia 15:127-138.

Winter, J. W., Bell, F. C., Pahl, L. I., and R. G. Atherton. 1987. Rainforest clearfelling in northeastern Australia. Proceedings of the Royal Society of Queensland 98:41-57.

Woinarski, J. C. Z., and A. J. Ash. 2002. Responses of vertebrates to pastoralism, military land use and landscape position in an Australian tropical savanna. Austral Ecology 27:311-323. 
Table 1. Attributes of reforested and reference sites surveyed for reptiles in tropical and subtropical Australia

\begin{tabular}{lccccc}
\hline Site type & Code & No. of tree & Age & \multicolumn{2}{c}{ No. of replicate sites } \\
& & spp planted & (years) & Tropics & Subtropics \\
& & - & $>50$ & 5 & 5 \\
\hline Pasture (reference) & P & - & $10-40$ & 5 & 5 \\
Regrowth & RG & 1 & $5-15$ & 5 & 5 \\
Monoculture plantations (young) & YP & & & & 5 \\
Cabinet timber plantations & CT & $6-20$ & $5-10$ & 5 & 10 \\
Ecological restoration plantings & ER & $20-100$ & $6-22$ & 10 & 9 \\
Monoculture plantations (old) & OP & 1 & $38-70$ & 10 & 10 \\
Rainforest (reference) & F & - & - & 10 & 10 \\
\end{tabular}


Table 2. Abundance and microhabitat use of reptiles recorded in reforested and rainforest reference sites in tropical and subtropical Australia.

a) tropics

\begin{tabular}{|c|c|c|c|c|c|c|c|c|c|c|c|c|c|}
\hline \multirow[t]{2}{*}{ Family and taxon $^{1}$} & & \multirow{2}{*}{$\begin{array}{l}\text { Habitat } \\
\text { pref. }^{2}\end{array}$} & \multicolumn{6}{|c|}{ Mean abundance per site type ${ }^{3}$} & \multicolumn{5}{|c|}{ Individuals per micro-habitat $^{4}$} \\
\hline & & & RG & YP & CT & ER & $\mathrm{OP}$ & $\mathrm{F}$ & LL & LO & RO & TR & WA \\
\hline A Hypsilurus boydii & Boyd's forest dragon & $\mathrm{R}$ & & & & & 0.5 & 0.1 & 2 & 2 & & 2 & \\
\hline S Eulamprus tigrinus & & $\mathrm{R}$ & & & & & & 0.8 & & 1 & & 7 & \\
\hline S Gnypetoscincus queenslandiae & prickly forest skink & $\mathrm{R}$ & & & & & 2.1 & 6.3 & & 83 & 1 & & \\
\hline S Lampropholis coggeri & & $\mathrm{R}$ & & & & 0.9 & 0.3 & 0.1 & 9 & 3 & 1 & & \\
\hline S Saproscincus basiliscus & & $\mathrm{R}$ & & & & 2.1 & 1.2 & 0.1 & 27 & 7 & & & \\
\hline S Saproscincus tetradactylus & & $\mathrm{R}$ & & & & & 0.4 & 0.2 & 3 & 2 & 1 & & \\
\hline S Saproscincus sp. & & $\mathrm{R}$ & & & & 0.1 & 0.8 & 0.6 & 11 & 4 & & & \\
\hline A Physignathus lesueurii & eastern water dragon & M & & & 0.2 & 0.7 & & & & & & & 8 \\
\hline S Lampropholis delicata & & M & & 0.4 & & & & & 2 & & & & \\
\hline S Carlia rubrigularis & & M & & 6.6 & 2.0 & 4.2 & 0.4 & 0.1 & 85 & 5 & & & \\
\hline B Morelia spilota & carpet python & M & 0.2 & & & & & & 1 & & & & \\
\hline C Tropidonophis mairii & freshwater snake & M & & & & 0.1 & & & 1 & & & & \\
\hline E Pseudechis porphyriacus & red-bellied black snake & M & 0.2 & 0.2 & & & & & 2 & & & & \\
\hline S Lampropholis sp. & & nd & & & & 1.6 & 0.2 & 0.1 & 18 & 1 & & & \\
\hline S Scincidae sp. & & nd & 0.6 & 3.2 & 0.6 & & 0.1 & 0.3 & 25 & 1 & 1 & & \\
\hline
\end{tabular}

${ }^{1}$ Families: lizards: A Agamidae, P Pygopodidae, S Scincidae, V Varanidae; snakes: B Boidae, C Colubridae, E Elapidae.

${ }^{2}$ Habitat preference: $\mathrm{R}=$ rainforest-dependent, $\mathrm{M}=$ mixed habitat; $\mathrm{nd}=$ not determined (see text).

${ }^{3}$ Site type: see Table 1.

${ }^{4}$ Microhabitat: $\mathrm{LL}=$ leaf litter (includes grass); $\mathrm{LO}=\log ; \mathrm{RO}=$ rock; $\mathrm{TR}=$ tree trunk, branch or buttress; WA = associated with watercourse. 
b) subtropics

\begin{tabular}{|c|c|c|c|c|c|c|c|c|c|c|c|c|c|}
\hline \multirow[t]{2}{*}{ Family and taxon $^{1}$} & & \multirow{2}{*}{$\begin{array}{l}\text { Habitat } \\
\text { pref. }^{2}\end{array}$} & \multicolumn{6}{|c|}{ Mean abundance per site type ${ }^{3}$} & \multicolumn{5}{|c|}{ Individuals per micro-habitat ${ }^{4}$} \\
\hline & & & RG & YP & $\mathrm{CT}$ & ER & OP & $\mathrm{F}$ & LL & LO & $\mathrm{RO}$ & TR & WA \\
\hline S Calyptotis lepidorostrum & & $\mathrm{R}$ & & & & & & 0.1 & & 1 & & & \\
\hline $\mathrm{S}$ Egernia major & land mullet & $\mathrm{R}$ & & & & & & 0.1 & 1 & & & & \\
\hline S Eulamprus murrayi & & $\mathrm{R}$ & & & & & & 0.5 & & 2 & & 3 & \\
\hline S Eulamprus sp. & & $\mathrm{R}$ & & & & & 0.2 & 1.0 & & 1 & 1 & 10 & \\
\hline S Ophioscincus ophioscincus & & $\mathrm{R}$ & & 0.2 & & & & & & 1 & & & \\
\hline S Ophioscincus truncatus & & $\mathrm{R}$ & & & & & & 0.1 & & 1 & & & \\
\hline S Saproscincus challengeri & & $\mathrm{R}$ & & 0.2 & & & & 0.1 & 1 & 1 & & & \\
\hline S Saproscincus spectabilis & & $\mathrm{R}$ & & 0.4 & & & & 0.1 & 2 & & & 1 & \\
\hline S Lampropholis couperi & & $\mathrm{R}$ & 0.2 & & & & 0.1 & & 2 & & & & \\
\hline E Tropidechis carinatus & rough-scaled snake & $\mathrm{R}$ & & & & & & 0.1 & 1 & & & & \\
\hline P Lialis burtonis & Burton's snake lizard & M & & & & 0.1 & & & 1 & & & & \\
\hline S Lampropholis amicula & & M & & & 0.1 & 0.8 & & & 8 & & & & \\
\hline S Lampropholis delicata & & M & 2.6 & & 1.5 & 5.8 & & 0.6 & 84 & 1 & 1 & & \\
\hline S Calyptotis scutirostrum & & M & & & & & 0.1 & & & 1 & & & \\
\hline S Saiphos equalis & & M & & & & & 0.1 & & & & 1 & & \\
\hline S Saproscincus mustelinus & & M & & & & 0.1 & & & 1 & & & & \\
\hline V Varanus varius & lace monitor & M & & & 0.1 & 0.1 & 0.1 & & 2 & & & 1 & \\
\hline B Morelia spilota & carpet python & $\mathrm{M}$ & & & & & & 0.1 & 1 & & & & \\
\hline C Dendrelaphis punctulata & common tree snake & M & & & & & 0.1 & & 1 & & & & \\
\hline E Demansia psammophis & yellow-faced whip snake & M & & & 0.1 & & & & 1 & & & & \\
\hline S Lampropholis sp. & & nd & 14.4 & 0.8 & 8.7 & 6.1 & 0.4 & 0.6 & 53 & 5 & 3 & & \\
\hline S Saproscincus sp. & & nd & 0.2 & 0.6 & & 0.1 & & 0.4 & 6 & 2 & & & \\
\hline S Scincidae sp. & & nd & & & 0.1 & 0.2 & 0.1 & & 3 & 1 & & & \\
\hline
\end{tabular}


Table 3. Variation amongst reforested and rainforest reference sites in tropical and subtropical Australia in (i) reptile species richness, (ii) richness within habitat-preference groups, (iii) total reptile abundance, and (iv) abundance of species and genera recorded at four or more sites (where a genus includes several species, or individuals identified only to genus). Oneway ANOVA $p$ determined by randomisation. Tropics $d f=5,39$; subtropics $d f=5,40$.

\begin{tabular}{lc}
\hline Dependent variable & $p$ \\
\hline Tropics: species richness & \\
All species & 0.037 \\
Rainforest species & $<0.001$ \\
Mixed habitat species & $<0.001$ \\
Tropics: abundance & \\
Total abundance & 0.17 \\
Hypsilurus boydii & 0.094 \\
Eulamprus tigrinus & $<0.001$ \\
Gnypetoscincus queenslandiae & $<0.001$ \\
Lampropholis coggeri & 0.55 \\
Saproscincus basiliscus & 0.093 \\
Physignathus lesueurii & 0.35 \\
Carlia rubrigularis & 0.020 \\
Saproscincus spp. total & 0.29 \\
Lampropholis spp. total & 0.45 \\
Subtropics: species richness & \\
All species & 0.092 \\
Rainforest species & $<0.001$ \\
Mixed habitat species & 0.16 \\
Subtropics: abundance & \\
Total abundance & 0.058 \\
Eulamprus murrayi & 0.004 \\
Lampropholis delicata & 0.42 \\
Eulamprus spp. total & $<0.001$ \\
Lampropholis spp. total & 0.034 \\
Saproscincus spp. total & 0.45 \\
\hline
\end{tabular}


Table 4. Microhabitat use by individuals of rainforest-dependent and mixed habitat reptiles in reforested and rainforest reference sites in tropical and subtropical Australia. The table shows the number of individuals observed in two categories of microhabitat, and associated $\chi^{2}$ values $(d f=1)$ for tests of independence of habitat preference and microhabitat.

\begin{tabular}{|c|c|c|c|c|}
\hline \multirow[t]{2}{*}{ Region } & \multirow[t]{2}{*}{ Habitat preference } & \multicolumn{2}{|c|}{ Microhabitat } & \multirow[t]{2}{*}{ Statistic } \\
\hline & & Trees, logs, rocks & Leaf litter, grass & \\
\hline \multirow[t]{2}{*}{ Tropics } & Rainforest & 114 & 52 & $\chi^{2}=96.3, p<0.001$ \\
\hline & Mixed-habitat & 5 & 91 & \\
\hline \multirow[t]{2}{*}{ Subtropics } & Rainforest & 21 & 8 & $\chi^{2}=61.7, p<0.001$ \\
\hline & Mixed-habitat & 5 & 99 & \\
\hline
\end{tabular}




\section{Legends to Figures}

Figure 1. Reptile species richness (mean, SE) in reforested and reference sites in tropical and subtropical Australia. Reptiles categorised by habitat preference: open bars = mixed habitat; closed bars $=$ rainforest-dependent. Individuals identified only to genus or family are not included, where taxa vary in habitat preference in study area. Site types: see Table 1.

Figure 2. Reptile abundance (mean, SE) in reforested and reference sites in tropical and subtropical Australia. Individuals are categorised by habitat preference: open bars $=$ mixed habitat; closed bars = rainforest-dependent; shaded bars = individuals identified only to genus or family, where taxa vary in habitat preference in study area. Site types: see Table 1.

Figure 3. Relationship between canopy cover and the richness of rainforest-dependent reptiles in reforested sites in tropical Australia. Canopy cover determined by visual estimate at five points per site (Kanowski et al. 2003). 

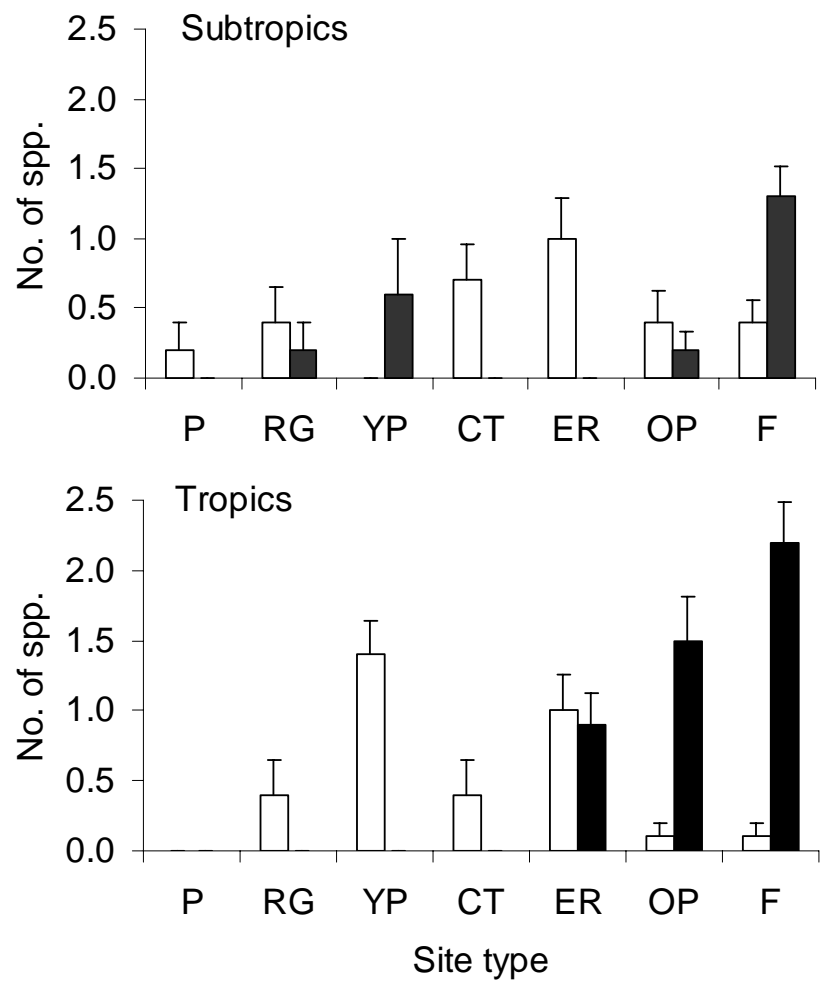

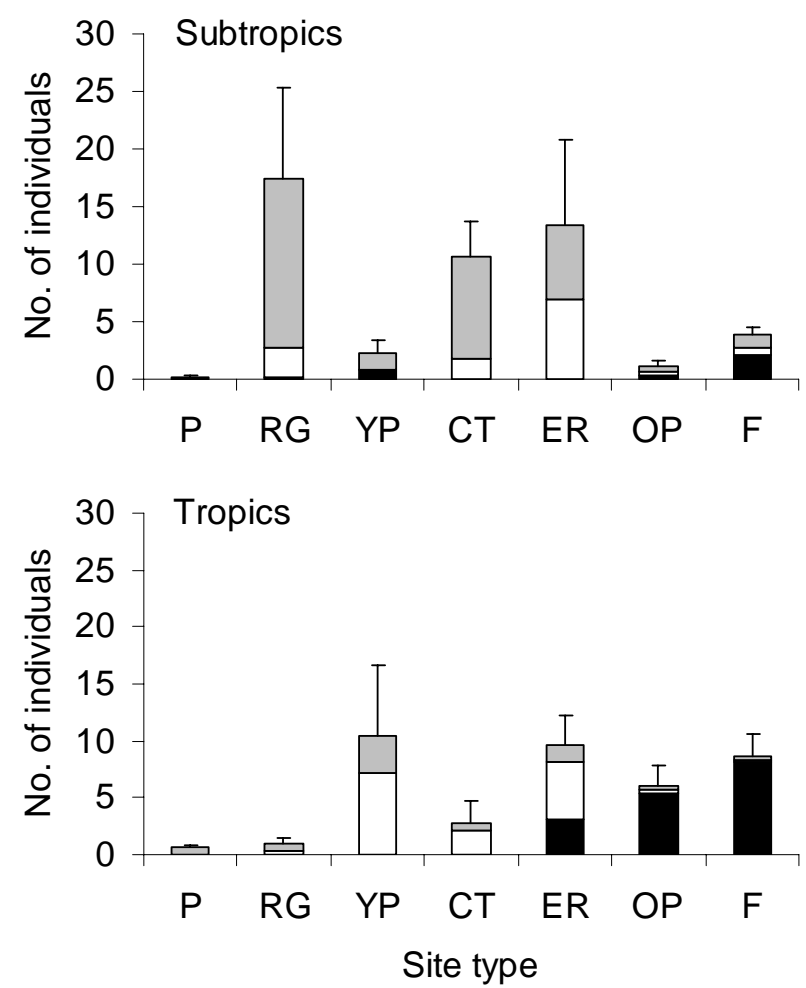


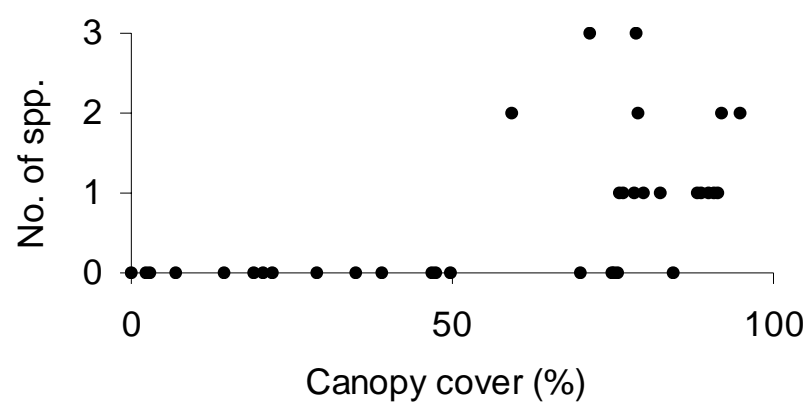

